\title{
Hearing handicap perception and hearing alterations in individuals with Parkinson's disease
}

\author{
Maysa Bastos Rabelo(1) \\ Márcia da Silva Lopes ${ }^{(1)}$ \\ Ana Paula Corona(1) \\ Roberto Paulo Correia de Araújo(1) \\ Ana Caline Nóbrega ${ }^{(1)}$
}

(1) Universidade Federal da Bahia, Salvador, Bahia, Brasil.

Conflict of interests: Nonexistent

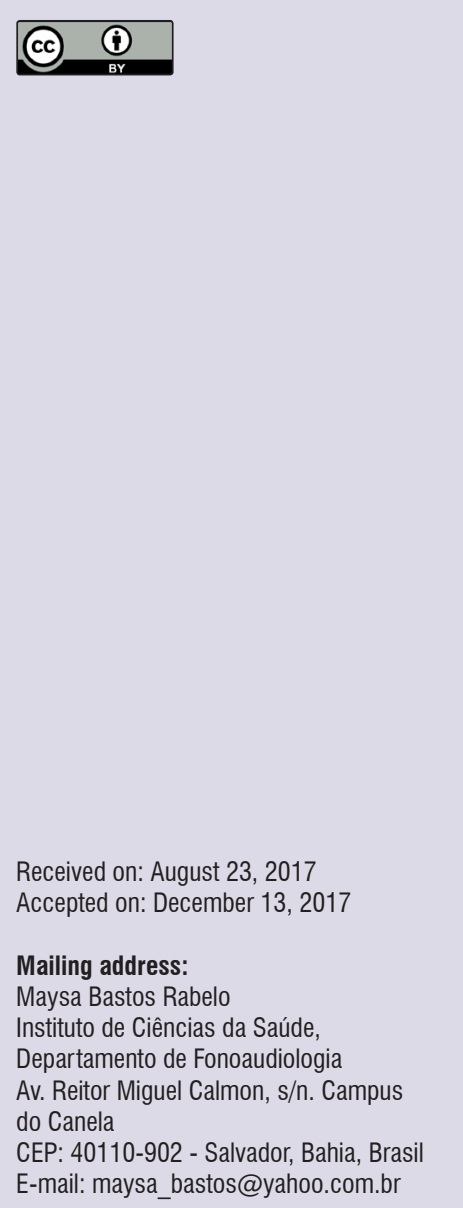

\section{ABSTRACT}

Purpose: to investigate the relationship between the perception of self-reported hearing impairment and the handicap with peripheral and central hearing alterations, in individuals with Parkinson's disease.

Methods: individuals with Parkinson's disease were seen and evaluated at a reference outpatient clinic for the treatment of movement disorders, between April and August 2015. All of them underwent basic audiological evaluation and hearing processing tests. The hearing handicap assessment was performed using the Hearing Handicap Inventory for the Elderly. As for the analysis of the relationship between hearing handicap perception and audiological, clinical and demographic variables, individuals were considered with or without perception, according to their score.

Results: thirty-three individuals, mostly males, with a mean age of 63.7 years, took part in the study. There was a high frequency $(n=31)$ of peripheral or central hearing alterations in the study population. However, only 14 reported some difficulty in hearing, eight not presenting hearing handicap perception, two having mild-moderate perception and four showing a significant perception.

Conclusion: the perceptions of hearing difficulties and the handicap are not related to audiological alterations in individuals presented with Parkinson's disease.

Keywords: Parkinson Disease; Hearing Loss; Aging; Questionnaires; Hearing Perception 


\section{INTRODUCTION}

Parkinson's disease (PD) is a degenerative disease of the central nervous system (CNS) associated with aging and characterized by the presence of resting tremors, muscular rigidity, bradykinesia, and postural instability ${ }^{1,2}$. The main cause of the symptoms is the lack of dopamine, a neurotransmitter synthesized in the brainstem ${ }^{3}$, which can result in biological, psychological, and social alterations ${ }^{4}$.

In addition to motor disturbances, PD patients may have several non-motor symptoms including depression, memory cognition, and speech alterations, which can interfere with their ability to communicate with others ${ }^{5,6}$. According to Zeigelboim et al. ${ }^{7}$, the degenerative processes in patients with PD can impact hearing either by compromising the internal ear or the CNS.

Hearing loss is the second most common dysfunction reported among the elderly according to the World Health Organization ${ }^{8}$. It affects approximately $1 / 3$ of people over the age of 65 years. Age-related degeneration of the auditory system can reduce hearing acuity making it harder to perceive sounds, especially in the presence of competitive noise, which can interfere with communication and social activities ${ }^{9,10}$.

In addition, hearing alterations can interfere with the psychosocial sphere of patients. Emotional and psychological impact can vary among patients according to life experiences, health expectations, and adaptability to limitations ${ }^{11}$.

Hearing alterations in PD patients can lead to hearing loss, which is an indication for psychosocial support and rehabilitation for communication. However, to start rehabilitation it is necessary to identify the auditory and psychosocial aspects involved through a thorough evaluation. In addition to the audiological evaluation, self-assessment questionnaires including hearing handicap inventory for the elderly (HHIE), which is prepared by Ventry and Weinstein ${ }^{12}$ and translated to Portuguese by Wieselberg ${ }^{13}$, are tools that can be used to assess the effects of hearing impairment on the emotional and social adjustment of elderly patients ${ }^{11,14}$.

Although the primary symptoms of PD patients are related to motor dysfunction, non-motor symptoms should be monitored since they can compromise their quality of lives. Despite identifying hearing loss in PD patients, it is not recognized as a non-motor sign of the disease. Thus, evaluating hearing in PD patients is limited to those who report symptoms related to it.
In view of the aforementioned, this study aimed to assess the relationship between the perception of selfreported hearing difficulties and peripheral and central auditory functions in PD patients. Furthermore, we aimed to identify the socio-demographic and clinical aspects related to the perception of hearing impairment.

\section{METHODS}

This is an observational, sectional study. It was approved by the Research Ethics Committee of the Prof. Edgard Santos University Hospital (HUPES) under protocol no. 843.890, and carried out between April and August of 2015. The study was performed in accordance with the ethical principles for research involving human beings, regulated by resolution no. 466/12. All participants or guardians signed the Informed Consent Form (ICF) prepared for the study.

\section{Study population}

The base population comprised patients with PD who were followed up at a reference clinic for the treatment of motor disturbances. Inclusion criteria included those with a confirmed diagnosis of idiopathic PD according to the United Kingdom PD Society Brain Bank criteria ${ }^{15}$. Patients with history of head trauma, stroke, severe psychiatric disturbances (schizophrenia, bipolar disorder, and depression), chronic ear diseases (otosclerosis, Meniére disease, endolymphatic hydrops, and hearing neuropathy), or diagnosis of vestibular schwannoma, dialytic chronic renal disease, and other neurodegenerative diseases were excluded. In addition, patients with Mini-Mental State Examination (MMSE) scores consistent with altered cognitive framework or those diagnosed with conductive or mixed hearing loss were excluded.

\section{Procedures and instruments for data collection}

The audiological status of patients was evaluated using meatoscopy. Afterwards, participants were administered MMSE questionnaires in Portuguese ${ }^{16}$. Those with scores lower than 24 and 18 for literate and illiterate patients, respectively, were excluded.

Clinical and demographic variables recorded included socio-demographic data, clinical manifestations of the disease, complaints, otoneurological history, and information related to their PD diagnosis. Staging was assessed with the Hoehn \& Yahr (H\&Y) scale by trained evaluators. H\&Y scale categorizes motor function into five progressive stages including: 
unilateral (stage I); bilateral (stage II); presence of tremor, rigidity, bradykinesia, and emergence of postural instability independent of gait (stage III), worsening of postural instability depending on aid for movement (stage IV), and serious disability of movement (stage $\mathrm{V})^{17}$.

Speech reception threshold tests were performed for the calculation of sensations levels for central auditory processing (CAP) to examine attention and reliability in the responses of individuals. In the elderly population, attention is affected by an extensive battery. Thus, three types of tests were used to evaluate CAP. For the tests, an MP3, coupled to an audiometer (AC40; Interacoustics, Middelfart, Denmark) was duly calibrated and used. Preceding the tests, the maximum output adjustment of the equipment was performed by calibrating the tone.

Using the standard duration test, 10 three-tone sequences of $50 \mathrm{~dB}$ SL (Decibels Sensation Level). were presented in a monaural way. Each sequence involved the presentation of long and short sounds in different combinations. Results obtained in the best ear were recorded and those with a percentage of less than $83 \%$ were classified as altered.

The dichotic digits test was performed using a 20 four-digit sequence from one to nine simultaneously presented to both ears at the intensity of $50 \mathrm{~dB}$ $\mathrm{SL}$. Subjects were instructed to verbally repeat the four numbers presented irrespective of order. Digits that were repeated correctly were recorded. Results were considered altered when the percentage of right answers was less than $60 \%$ and $78 \%$ for individuals with and without hearing loss, respectively.

For the gaps in noise test, six-millisecond (ms) white noise follow-ups were presented interrupted by zero to three silent intervals (gaps) with varying time between 0 and $20 \mathrm{~ms}$. The stimulus was emitted in a binaural form at a $50 \mathrm{~dB} S \mathrm{SL}$ intensity. The gap detection threshold was the lowest silent interval identified in $50 \%$ of the six presentations. A gap detection threshold higher than 8 $\mathrm{ms}^{18}$ was considered altered.

Following the CAP tests, pure tone audiometry was performed, according to the recommendations of the American speech-language-hearing association ${ }^{19}$ and the research of the speech recognition index. Audiograms were classified as normal, when all the thresholds obtained were equal to or less than 25 $\mathrm{dBHL}$ (Decibels Hearing Level) or as hearing loss when there was upper pure tone air threshold higher than 25 $\mathrm{dB} \mathrm{HL}$ on at least one frequency. In ears classified as hearing loss, the configuration was identified according to the classification of Silman and Silverman ${ }^{20}$, while the degree of hearing loss (mild, moderate, moderately severe, severe, or profound) was according to Lloyd and Kaplan ${ }^{21}$ considering the recommendations of the federal council of phonoaudiology ${ }^{22}$. Following pure tone audiometry, measures of acoustic immittance were obtained.-

Self-reported hearing difficulty was evaluated by asking patients "Do you think you are having trouble hearing?". Those who responded yes and showed alterations in audiological exams were evaluated for hearing impairment using the HHIE questionnaire, which contains 25 "yes", "sometimes", or "no" questions. Of the 25 questions, 13 with a maximum score of 52 evaluate the emotional consequences of hearing dysfunction and 12 with a maximum score of 48 evaluate the social/situational consequences. Results are interpreted according to the value of each item with 4 points or each "yes", 2 for "sometimes", and 0 for "no" answers. A score between 0-16 indicates no perception of the hearing impairment, 17-42 indicates mild to moderate perception, and greater or equal to 43 indicates a significant perception.

\section{Data analysis}

Data collected were organized and analyzed using EpiData software version 3.1 (EpiData Association, Odense, Denmark). The frequency of socio-demographic and clinical variables, otoneurological complaints, and disease duration (determined from the onset of the first symptoms) were recorded. Analysis of the results of the audiological evaluations (peripheral and central) in relation to complaints of hearing difficulties was performed. For the purpose of the analysis, the following variables were dichotomized: age (younger than 60 years and over than 60 years), educational level (completed primary for illiterate and completed high school, or higher education for literate patients), and employment status (yes or no depending on the current formal or informal employment report). In addition, patients were grouped according to the stages of H\&Y at initial PD diagnosis (Stages I and II) and advanced PD (Stages III, IV, and V). The duration of symptoms was categorized into less than 10 years and over 10 years, considering a median.

For the analysis of the relationship between the perception of hearing impairment and audiological, clinical, and demographic variables, a score equal to or less than 16 in the HHIE was considered without 
perception, while that equal to or greater than 17 were considered with perception. Audiometric thresholds were analyzed using the results obtained from the best ear and considering the social auditory behavior of the patient. For this analysis, audiometric thresholds were classified into $M_{1}$ (average of 500,1000 , and $2000 \mathrm{~Hz}$ ), $M_{2}$ (average of 2000, 3000, and $4000 \mathrm{~Hz}$ ), and high frequencies (average of the frequency thresholds of 6000 and $8000 \mathrm{~Hz}$ ) with values above $25 \mathrm{~dB}$ considered altered. CPA tests were considered altered when at least one of the three exams performed was outside of normal values.

Due to the non-probabilistic sample plan, the descriptive analysis of the data was performed and the statistical associations were verified using the Yule's $Q$ coefficient to measure the degree of association between dependent (hearing handicap) and independent (socio-demographic and clinical factors) variables. The coefficient varied from -1 to +1 where up to 0.1 indicated an absence of association, 0.1 to 0.29 weak association, 0.3 to 0.49 moderate association, and 0.5 to 1.0 indicated a strong association ${ }^{23,24}$. In addition, Kendall-Stuart Tau-c and Tau-b correlation coefficients were used ${ }^{25}$. The classification of the statistical association force was similarly classified where values from 0 to 0.09 indicated an absence of association, 0.1 to 0.29 weak association, 0.3 to 0.49 moderate association, and 0.5 to 1.0 strong association. Cohen's $\mathrm{h}$ index was calculated ${ }^{26}$ to verify a statistical difference between the with and without perception of hearing impairment groups for the CAP tests. For the purpose of this analysis, it was considered without effect when $h$ was up to 0.2 , weak effect when $h$ was between 0.2 and 0.49 , moderate effect when $h$ was between 0.5 and 0.79 , and strong effect when $\mathrm{h}$ was more than 0.8 .

\section{RESULTS}

Eighty-seven patients with PD were contacted. Among those, 29 were not located due to outdated phone records, 15 refused to participate in the survey, 5 were deceased at the time of contact, 2 did not meet the inclusion criteria, and 3 were excluded due to mixed hearing loss on pure tone audiometry. The final study population comprised 33 PD patients, who were mostly males $(n=22)$ between the ages of 42 and 85 years with an average age of 63.7 years. The average disease duration was 9.2 years with most individuals belonging to PD stage II $(n=15)$, followed by stage I $(n=10)$, stage III $(n=7)$, and stage IV $(n=1)$. Otoneurological complaints reported were most often dizziness $(n=16)$, followed by hearing difficulties $(n=15)$, and tinnitus $(n=6)$.

Results of the audiological evaluations revealed that 31 out of 33 patients had alterations in at least one of the auditory tests performed. However, less than half $(n=14)$ of those reported hearing difficulties. In patients showing alterations in pure tone audiometry and CPA, more than half $(n=10)$ reported hearing difficulties. Most patients with alterations in just one test did not report hearing difficulties (Table 1).

Table 1. Perception of hearing difficulty and alterations in audiological evaluations

\begin{tabular}{cccccc}
\hline \multirow{2}{*}{ Hearing difficulty } & \multicolumn{7}{c}{ Altered $(\mathbf{n}=\mathbf{3 1})$} & Unaltered $(\mathbf{n}=\mathbf{2})$ \\
\cline { 2 - 6 } & PTA $\mathbf{n}=\mathbf{6}$ & CAP $\mathbf{n}=\mathbf{7}$ & PTA and CAP $\mathbf{n = 1 8}$ & PTA or CAP $\mathbf{n = 3 1}$ & PTA and CAP $\mathbf{n = 2}$ \\
\hline No & $4 / 6$ & $6 / 7$ & $8 / 18$ & $17 / 31$ & $1 / 2$ \\
Yes & $2 / 6$ & $1 / 7$ & $10 / 18$ & $14 / 31$ & $1 / 2$ \\
\hline
\end{tabular}

FSource: Research data.

PTA, pure tone audiometry; CAP, central auditory processing

The HHIE questionnaire was administered to 14 patients who reported hearing difficulties. Of those, 8 did not perceive difficulty in hearing, 2 perceived mild-moderate difficulties, and 4 perceived significant difficulty in hearing. Figure 1 shows the distribution of scores in the questionnaire according to the social/ situational, emotional, and total score scales. Results showed that social/situational scores were higher compared to emotional scores. In addition, a high variability in the total score ranging from zero to 92 was noted. 


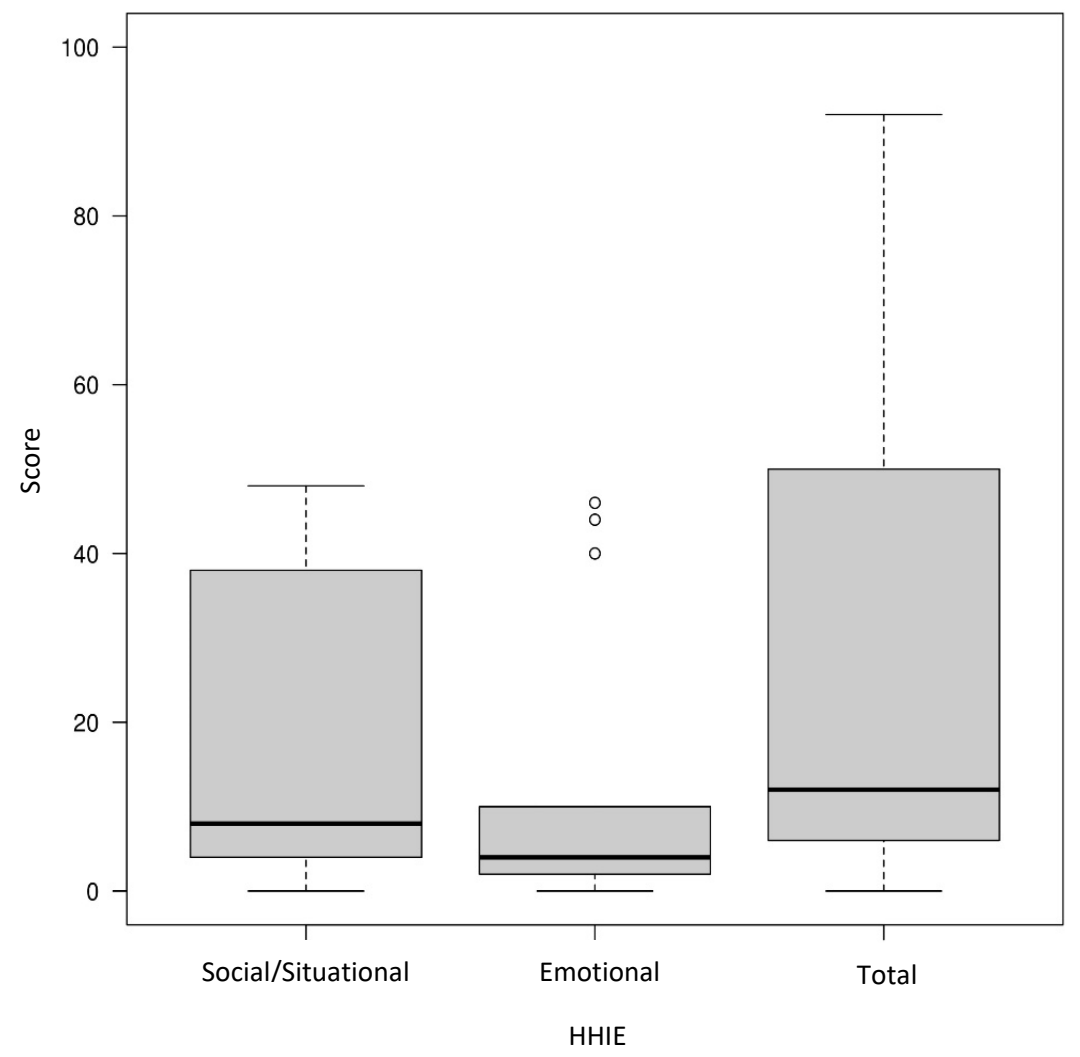

Source: Research data

HHIE, hearing handicap inventory for the elderly

Figure 1. Hearing handicap inventory for the elderly score as per the scales

On analyzing the patients' perception of hearing, 13 out of the 14 patients who responded to the questionnaire had hearing loss with only 1 patient showing an alteration in CPA. Of those, only 2 showed audiometric patterns that allowed the classification of the degree of hearing loss (alteration in $\mathrm{M}_{1}$ ) with light grade hearing loss in the best ear. It was observed that most patients had a light descending audiometric configuration, which is corroborated by the higher frequency of alterations in $\mathrm{M}_{2}$ or higher frequencies. In addition, the analysis of the perception of the hearing impairment in relation to the observed audiological alterations, revealed a similar distribution between those who perceived or did not perceive the impairment (Table 2). Moreover, there was a weak association between the perception of the impairment and the audiological alterations, which is characteristic of hearing loss in CPA tests. 
Table 2. Perception of hearing handicap and frequency of audiological alterations

\begin{tabular}{cccc}
\hline \multirow{2}{*}{ Audiological alterations } & \multicolumn{2}{c}{ Hearing impairment $(\mathbf{n}=14)$} & Tau-c \\
\cline { 2 - 4 } & With perception & Without perception & -0.18 \\
Hearing loss & $8 / 13$ & $5 / 13$ & \\
$\mathrm{M}_{1}$ & $1 / 2$ & $1 / 2$ & \\
$\mathrm{M}_{2}$ and high frequencies & $4 / 7$ & $3 / 7$ & Tau-b \\
High frequencies & $3 / 4$ & $1 / 4$ & -0.33 \\
\hline Configuration of hearing loss & & & \\
Light descending & $4 / 9$ & $5 / 9$ & \\
Pronounced descending & $1 / 1$ & 0 & Cohen's h \\
Not classifiable* & $3 / 3$ & 0 & 0.18 \\
\hline CAP Tests & $6 / 11$ & $5 / 11$ & \\
\hline
\end{tabular}

Source: Research data.

PD, Parkinson's disease; CAP, central auditory processing; M1, mean of 500, 1000, and $2000 \mathrm{~Hz}$ frequencies; M2, mean of 2000, 3000, and 4000 Hz frequencies; High frequencies, 6 or $8 \mathrm{kHz}$ thresholds

* Patients with hearing loss who did not fit the definition of the authors for configuration (Silman and Silverman, 1997).

Table 3 shows the socio-demographic and clinical factors related to hearing in patients aged over 60 years, with education up to primary level, and who were unemployed. It was noted that patients who had perception of hearing disturbances were more often in the initial stages of the disease and were diagnosed for 10 years or more. Moreover, individuals who did not report tinnitus and complained of dizziness had greater perception. The analysis of the Yule's $Q$ coefficient revealed a strong association between the educational level, employment status, disease staging, and duration of symptoms with the perception of hearing impairment. 
Table 3. Socio-demographic and clinical factors related to the perception of the hearing impairment

\begin{tabular}{|c|c|c|c|}
\hline \multirow{2}{*}{ Variables } & \multicolumn{2}{|c|}{ Hearing handicap $(n=14)$} & \multirow{2}{*}{ Yule's Q } \\
\hline & Without perception & With perception & \\
\hline Age (years) & & & -0.20 \\
\hline Less than 60 & $2 / 4$ & $2 / 4$ & \\
\hline Over 60 & $6 / 10$ & $4 / 10$ & \\
\hline Gender & & & -0.25 \\
\hline Females & $3 / 6$ & $3 / 6$ & \\
\hline Males & $5 / 8$ & $3 / 8$ & \\
\hline Education level & & & $-0.53^{*}$ \\
\hline Up to primary school & $3 / 8$ & $5 / 8$ & \\
\hline $\begin{array}{c}\text { Completed high school or } \\
\text { higher education }\end{array}$ & $4 / 6$ & $2 / 6$ & \\
\hline Work & & & $1.00^{*}$ \\
\hline Yes & $2 / 2$ & $0 / 2$ & \\
\hline No & $6 / 12$ & $6 / 12$ & \\
\hline PD Staging & & & $0.68^{*}$ \\
\hline Initial & $7 / 11$ & $4 / 11$ & \\
\hline Advanced & $1 / 3$ & $2 / 3$ & \\
\hline $\begin{array}{l}\text { Onset of the Symptoms } \\
\text { (years) }\end{array}$ & & & $0.71^{*}$ \\
\hline Less than 10 & $6 / 8$ & $2 / 8$ & \\
\hline More than 10 & $2 / 6$ & $4 / 6$ & \\
\hline Tinnitus & & & 0.25 \\
\hline Yes & $2 / 3$ & $1 / 3$ & \\
\hline No & $6 / 11$ & $5 / 11$ & \\
\hline Dizziness & & & 0.33 \\
\hline Yes & $4 / 8$ & $4 / 8$ & \\
\hline No & $4 / 6$ & $2 / 6$ & \\
\hline
\end{tabular}

Source: Research data.

PD, Parkinson's disease

*Strong association

\section{DISCUSSION}

Our results revealed that despite the large number of PD patients with audiological alterations, most of them did not report hearing difficulties. This was similar to the results by Vitale et al. ${ }^{27}$, in which the authors reported that although PD patients presented with higher than normal hearing thresholds, they did not report hearing difficulties. Additionally, other studies reported an impairment of the peripheral and central auditory systems in PD patients $\mathrm{s}^{7,28-30}$.

It is believed that in PD patients, the perception of sensory impairments may be affected by diseaserelated motor dysfunctions. In addition, the audiometric profile of PD patients observed in this study, which was corroborated by previous studies ${ }^{31,32}$ was a sensorial-neural hearing loss with greater impairment of audiometric thresholds in high frequencies. Studies revealed that inability to follow conversations in noisy settings may be due to hearing loss in high frequencies and not necessarily correspond a decrease in auditory acuity perception ${ }^{9}$. In addition, this audiological profile of PD patients was similar to that observed in presbycusis patients. It is therefore believed that the inability to perceive the hearing impairment may be due to additional factors including the age- related progressive nature of hearing loss.

In addition, it is hypothesized that age is a factor contributing to the inability of PD patients to acknowledge having hearing difficulties. In our study, most of the patients were older than 60 years-old. With hearing impairment being the second most common chronic condition reported among the elderly population $^{8}$, it is believed that hearing impairment and its sequelae are strongly associated with the aging 
process. Aging in the western culture has a social stigma, which can isolate patients ${ }^{31}$. Therefore, not acknowledging or minimizing a hearing impairment may be due to patients' denial of the condition and not necessarily the absence of it.

Hearing difficulty can impact patients both socially and emotionally, which can interfere with their quality of lives. Therefore, assessing patients' abilities to acknowledge their own hearing impairment can measure its impact on their daily lives. In this study, patients reported a greater impact on the social compared to the emotional aspects of their lives. Santiago and Novaes ${ }^{32}$ reported that patients' quality of lives can be greatly impacted in situations where they are unable to communicate with others. In addition, auditory alterations can limit the information acquired through the media to certain outlets. Moreover, it is believed that due to the limitations imposed by motor and non-motor manifestations of the disease, PD patients tend to leave the working environment, which can contribute to their social isolation.

We could only find one study that administered the hearing impairment questionnaire to PD patients. In this study, Folmer et al. ${ }^{33}$ compared the auditory functions of $35 \mathrm{PD}$ patients to 35 control subjects. The authors reported that PD patients scored higher (18.6) compared to the control group (14.1). Furthermore, similar to our results, the authors reported that less than half of PD patients (44\%) had some perception of their hearing impairment, whereas a smaller number (25\%) was noted in the control group. Therefore, it is still believed that only a small number of individuals are able to confront having an impairment, which agrees with our results.

Otoneurological complaints including dizziness and tinnitus are often described in the literature as part of the normal aging process ${ }^{34,35}$. Such complaints were described in PD patients in a study conducted by Bassetto et al..$^{36}$ It is known that aging contributes to several changes in the CNS including the ability to process proprioceptive, vestibular, and visual signs, which can lead to symptoms as dizziness, especially in PD patients, in whom alterations in postural control are more evident due to the disease ${ }^{36,37}$. Accordingly, these impairments can limit their daily activities and consequently worsen their quality of lives. A large number of PD patients who reported having dizziness acknowledged having a hearing impairment, which may be a result of social isolation. In addition, those who did not report tinnitus acknowledged having a hearing impairment. This may be due to tinnitus masking the ability to perceive having a hearing impairment.

This study has some limitations. First, the sample size was small. In addition, a small number of patients participated in the HHIE questionnaire, which may be due to difficulties in accessing health services as a result of motor alterations associated with PD. Moreover, since a small number people were able perceive their hearing difficulties, their evaluation using the HHIE was not appropriate as this questionnaire is intended for those who report having hearing difficulties. Finally, the study population only included outpatients, which does not allow us to extrapolate the results to other populations or to infer that hearing impairments are due to PD. However, it should be noted that the study met its proposed objectives of assessing the relationship between the perception of self-reported hearing difficulties and the peripheral and central audiological alterations, in addition to verifying socio-demographic and clinical aspects related to the perception of hearing impairment in patients with PD. However, more research is needed to elucidate the role of PD in these results.

This study emphasizes the need to include audiological evaluations as part of the routine examination for patients with PD, especially that perception of hearing impairment may not be related to audiological findings. Furthermore, assessing the severity of the impairment can lead to early and effective auditory rehabilitation that can minimize prejudice especially socially, which can impact patients' quality of lives.

\section{CONCLUSION}

The results of this study revealed that the perception of hearing impairment and hearing difficulties are not related to the presence of peripheral and central audiological alterations in PD patients. Factors that seemed to contribute to a better perception of hearing impairment is lower educational levels, unemployment, advanced stages of PD, and longer duration of disease symptoms.

\section{REFERENCES}

1. De Lau LML, Breteler MM. Epidemiology of Parkinson's disease. Lancet Neurol. 2006;5(6):525-35.

2. Rosso ALZ, Nicaretta DH, Mattos JP. Anatomoclinical correlation in Parkinson's disease. Rev Bras Neurol. 2008;44(4):41-7. 
3. Limongi JCP. Conhecendo melhor a doença de Parkinson: uma abordagem multidisciplinar com orientações práticas para o dia-a-dia. 1 Ed. São Paulo: Plexus; 2001.

4. Miranda ES, Pereira LD, Bommarito S, Silva TM. Avaliação do processamento auditivo de sons não-verbais em indivíduos com doença de Parkinson. Rev Bras Otorrinolaringol. 2004;70(4):534-9.

5. Krishnan S, Sarma G, Sarma S, Kishore A. Do nonmotor symptoms in Parkinson's disease differ from normal aging? Mov Disord Clin Pract. 2011;26(11):2110-3.

6. Poewe W. Non-motor symptoms in Parkinson's disease. Eur J Neurol. 2008;15(Suppl 1):14-20.

7. Zeigelboim BS, Klagenberg KF, Muñoz MB, Gorski LP, Teive HAG, Santos RS. Evaluation of central auditive processing in patients with Parkinson disease. Arq Int Otorrinolaringol. 2011;15(2):189-94.

8. World Health Organization. Global brief for world health day 2012. [cited 2017 Aug 10]. Available from: http://apps.who.int/iris/bitstream/10665/70853/1/ WHO_DCO_WHD_2012.2_eng.pdf

9. Coser MJS, Cioquetta E, Pedroso FS, Coser PL. Cortical auditory evoked potentials in elderly with difficulty in speech understanding complaint. Arq Int Otorrinolaringol. 2007;11(4):396-401.

10. Calais LL, Russo ICP, Borges ACLC. Performance of elderly in a speech in noise test. Pró-Fono R. Atual. Científ. 2008;20(3):147-52.

11. Lima II, Aiello CP, Ferrari DV. Correlações audiométricas do questionário de handicap auditivo para adultos. Rev. CEFAC. 2011;13(3):496-503.

12. Ventry IM, Weinstein BE. The hearing handicap inventory for the elderly: a New Tool. Ear Hear. 1982;3(3):128-34.

13. Wieselberg MB. A auto-avaliação do handicap em idosos portadores de deficiência auditiva: o uso do HHIE [Dissertação]. São Paulo (SP): Pontifícia Universidade Católica de São Paulo; 1997.

14. Cassol M, Ferreira MIDC, Poglia DMA. Use of the hhie-s questionnaire associated with vocal and audiological evaluation in the elderly group. Estud Interdiscip Envelhec. 2007;12(1):81-95.

15. Hughes AJ, Daniel SE, Kilford L, Lees AJ. Accuracy of clinical diagnosis of idiopathic Parkinson's disease: a clinic-pathological study of 100 cases. J. Neurol. neurosurg. Psychiatry. 1992;55(3):181-4.
16. Almeida OP. Mini exame dos estado mental e o diagnóstico de demência no Brasil. Arq Neuropsiquiatr. 1998;56(3B):605-12.

17. Hoehn MM, Yahr MD. Parkinsonism: onset, progression and mortality. Neurology. 1967;17(5):427-42.

18. Liporaci FD, Frota SMMC. Resolução temporal auditiva em idosos. Rev Soc Bras Fonoaudiol. 2010;15(4):533-9.

19. ASHA: American Speech Languag e Hearing Association (2005). Guidelines for manual Puretone threshold audiometry. [cited 2017 Aug 10]. Available from: http://www.asha.org/policy/gl200500014.htm

20. Silman S, Silverman CA. Basic audiologic testing. In: Silman S, Silverman CA. Auditory diagnosis: principles and applications. $1 \mathrm{Ed}$. San Diego: Singular Publishing Group; 1997.

21. Lloyd LL, Kaplan H. Audiometric interpretation: a manual o basic audiometry. 1 Ed. Baltimore: University Park Press; 1978.

22. Sistema de Conselhos Federal e Regionais de Fonoaudiologia. Guia de Orientações na Avaliação Audiológica Básica (2017). [cited 2017 Aug 10]. Available from: http://www.crefono4.org.br/cms/ files/Anexos/manualdeaudiologia.pdf

23. Cohen J. Statistical power analysis for the behavioral sciences. 2 Ed. Hillsdale: Lawrence Erlbaum; 1988.

24. Garson GD. Measures of Association. 1. ed. Asheboro: Statistical Associates Publishers; 2012. 25. Yule GU. On the methods of measuring association between two attributes. Journal of the Royal Statistical Society. 1912;76(6):579-652.

26. Agresti A. Categorical Data Analysis. 3 Ed. Hoboken: Wiley; 2012.

27. Vitale C, Marcelli V, Allocca R, Santangelo G, Riccardi $\mathrm{P}$, Erro $\mathrm{R}$ et al. Hearing impairment in Parkinson's disease: expanding the nonmotor phenotype. Mov Disord. 2012;27(10):1530-5.

28. Yýlmaz S, Karalý E, Tokmak A, Güçlü E, Koçer A, Oztürk O. Auditory evaluation in Parkinsonian patients. Eur Arch Otorhinolaryngol. 2009;266(5):669-71 .

29. Troche J, Troche MS, Berkowitz R, Grossman $\mathrm{M}$, Reilly J. Tone discrimination as a window into acoustic perceptual deficits in Parkinson's disease. Am J Speech Lang Pathol. 2012;21(3):258-6.

30. Pisani V, Sisto R, Moleti A, Di Mauro R, Pisani A, Brusa $L$ et al. An investigation of hearing impairment 
in de-novo Parkinson's disease patients: A preliminary study. Parkinsonism Relat Disord. 2015;21(8):987-91.

31. Moreira V, Nogueira FNN. From the inevitable to the undesirable: The experience of the stigma of the aging process in the contemporary world. Psicol. 2008;19(1):59-79.

32. Santiago LM, Novaes CO. Auto-avaliação da audição em idosos. Rev. CEFAC. 2009;11(Suppl. 1):98-105.

33. Folmer RL, Vachhani JJ, Theodoroff SM, Ellinger R, Riggins A. Auditory Processing Abilities of Parkinson's Disease Patients. BioMed Research International. 2017;2017(1):1-10.

34. Ruwer SL, Rossi AG, Simon LF. Balance in the elderly. Rev Bras Otorrinolaringol. 2005;71(3):298-303.

35. Ferreira LMBM, Junior ANR, Mendes EP. Characterization of tinnitus in the elderly and its possible related disorders. Rev Brasil Otorrinolaringol. 2009;75(2):249-55.

36. Bassetto JM, Zeigelboim BS, Jurkiewicz AL, Klagenberg KF. Neurotological findings in patients with Parkinson's disease. Rev Bras Otorrrinolaringol. 2008;74(3):350-5.

37. Zeigelboim BS, Jurkiewicz AL, Fukuda Y, Mangabeira-Albernaz PL. Alterações vestibulares em doenças degenerativas do sistema nervoso central. Pró-Fono R. Atual. Cient. 2001;13(2):263-70. 